\title{
Complex laterally ordered InGaAs and InAs quantum dots by guided self-organized anisotropic strain engineering on shallow- and deep-patterned GaAs (311)B substrates
}

\section{Citation for published version (APA):}

Selcuk, E., Hamhuis, G. J., \& Nötzel, R. (2007). Complex laterally ordered InGaAs and InAs quantum dots by guided self-organized anisotropic strain engineering on shallow- and deep-patterned GaAs (311)B substrates. Journal of Applied Physics, 102(9), 094301-1/5. [094301]. https://doi.org/10.1063/1.2801364

DOI:

10.1063/1.2801364

Document status and date:

Published: 01/01/2007

\section{Document Version:}

Publisher's PDF, also known as Version of Record (includes final page, issue and volume numbers)

\section{Please check the document version of this publication:}

- A submitted manuscript is the version of the article upon submission and before peer-review. There can be important differences between the submitted version and the official published version of record. People interested in the research are advised to contact the author for the final version of the publication, or visit the DOI to the publisher's website.

- The final author version and the galley proof are versions of the publication after peer review.

- The final published version features the final layout of the paper including the volume, issue and page numbers.

Link to publication

\footnotetext{
General rights

- You may freely distribute the URL identifying the publication in the public portal. follow below link for the End User Agreement:

www.tue.nl/taverne

\section{Take down policy}

If you believe that this document breaches copyright please contact us at:

openaccess@tue.nl

providing details and we will investigate your claim.
}

Copyright and moral rights for the publications made accessible in the public portal are retained by the authors and/or other copyright owners and it is a condition of accessing publications that users recognise and abide by the legal requirements associated with these rights.

- Users may download and print one copy of any publication from the public portal for the purpose of private study or research.

- You may not further distribute the material or use it for any profit-making activity or commercial gain

If the publication is distributed under the terms of Article $25 \mathrm{fa}$ of the Dutch Copyright Act, indicated by the "Taverne" license above, please 


\title{
Complex laterally ordered InGaAs and InAs quantum dots by guided self-organized anisotropic strain engineering on shallow- and deep-patterned GaAs (311)B substrates
}

\author{
E. Selçuk, ${ }^{\text {a) }}$ G. J. Hamhuis, and R. Nötzel \\ COBRA Inter-University Research Institute, Eindhoven University of Technology, \\ 5600MB Eindhoven, The Netherlands
}

(Received 6 July 2007; accepted 31 August 2007; published online 1 November 2007)

\begin{abstract}
Self-organized anisotropic strain engineering guided on shallow- and deep-patterned GaAs (311)B substrates is exploited for formation of complex laterally ordered architectures of connected InGaAs quantum dot (QD) arrays and isolated InAs QD groups by molecular beam epitaxy. The combination of strain and step engineerings on shallow stripe-patterned substrates transforms the periodic spotlike arrangement of the InGaAs QD arrays and InAs QD groups (on planar substrates) into a zigzag arrangement of periodic stripes which are well ordered over macroscopic areas on zigzag mesa-patterned substrates. In contrast, the formation of slow-growing facets on deep-patterned substrates produces QD-free mesa sidewalls, while InGaAs QD arrays and InAs QD groups form on the GaAs (311)B top and bottom planes with arrangements modified only close to the sidewalls depending on the sidewall orientation. The QDs on the shallow- and deep-patterned substrates exhibit excellent optical properties up to room temperature. Therefore, the concept of guided self-organization demonstrated on shallow-patterned (due to steps) and deep-patterned (due to facets) substrates is highlighted for creation of complex architectures of laterally ordered QDs for future quantum functional devices. (C) 2007 American Institute of Physics.
\end{abstract}

[DOI: 10.1063/1.2801364]

\section{INTRODUCTION}

The lateral ordering of epitaxially grown semiconductor quantum dots (QDs) with high optical and electronic quality is essential for the realization of future quantum functional devices with well-designed control of the quantum mechanical and electromagnetic interactions of single and multiple electrons and photons. ${ }^{1-4}$ We have developed a concept for the lateral ordering of semiconductor QDs based on selforganized anisotropic strain engineering of $\mathrm{InGaAs} / \mathrm{GaAs}$ superlattice (SL) templates. During SL template formation the InGaAs QD growth, thin GaAs capping, annealing, GaAs spacer layer growth, and stacking produce well-ordered one-[on GaAs (100)] and two-dimensional [on GaAs (311)B] InGaAs distributions on a mesoscopic length scale. This is caused by anisotropic adatom surface migration during annealing and vertically and laterally strain correlated growth during stacking. ${ }^{5,6}$ The related lateral strain field modulation on the surface of the SL template governs InGaAs QD ordering due to local strain recognition. ${ }^{7,8}$ Linear arrays of InGaAs QDs are formed on GaAs (100), whereas spotlike arrangements of connected InGaAs QD arrays and isolated InAs QD groups with controllable number of QDs are formed on GaAs (311)B, exhibiting excellent optical properties. The concept of self-organized anisotropic strain engineering for QD ordering has been extended for formation of more complex architectures of lateral QD arrays by combining it with step engineering on shallow-patterned sub-

\footnotetext{
a) Author to whom correspondence should be addressed. Tel.: +31 40247 4872. FAX: +31 40246 1339. Electronic mail: e.selcuk@tue.nl
}

strates. The monolayer-height steps generated on the shallow-patterned substrates with pattern sizes of micrometer length scales modify the SL template formation to form wellpositioned bends and branches of linear QD arrays on GaAs (100) and transform the spotlike InGaAs QD arrangement on GaAs (311)B into a characteristic zigzag arrangement. ${ }^{9,10}$ The pattern sizes are clearly larger than adatom surface migration lengths $(\leqslant 1 \mu \mathrm{m})$ and strain field decay lengths (several $10 \mathrm{~nm}$ ) governing the self-organization process. Hence, guided self-organization is introduced for the lateral ordering of QDs in complex architectures to create the building blocks for future quantum functional devices.

In this paper, we generalize this demonstration of guided self-organization to the lateral ordering of InGaAs, as well as InAs QDs, on shallow- and deep-patterned GaAs (311)B substrates. Similar to the InGaAs QD arrays, the isolated InAs QD groups on shallow stripe-patterned substrates are arranged in zigzags of periodic stripes which become well ordered over macroscopic areas on zigzag patterned substrates. In contrast, the formation of slow-growing facets on deep-patterned substrates produces mesa sidewalls free of QDs, while InGaAs QD arrays and InAs QD groups (coalesced into single QDs at increased growth temperature) develop on the GaAs (311)B top and bottom planes. Their spotlike arrangement is modified only close to the sidewalls depending on the sidewall orientation. The QDs on the shallow- and deep-patterned substrates exhibit excellent optical properties up to room temperature (RT) highlighting the complementary nature of guided self-organization on 

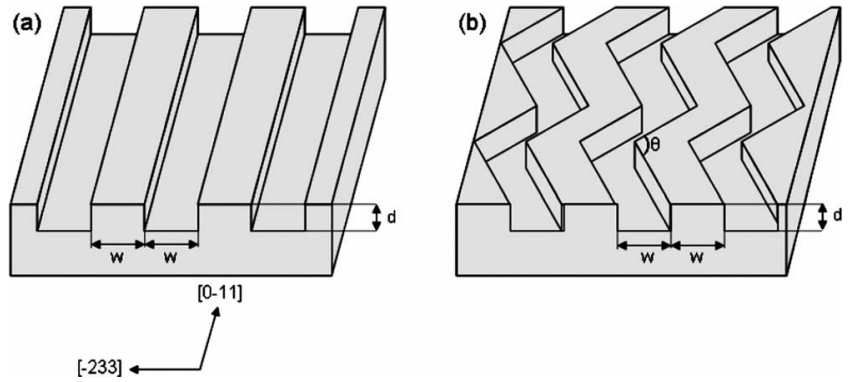

FIG. 1. Schemes of the (a) [01-1] stripe-patterned GaAs (311)B substrate with stripe widths and separations $(w)$ between 2 and $10 \mu \mathrm{m}$ and (b) zigzagpatterned GaAs (311)B substrates with $10 \mu \mathrm{m}$ width $(w)$ and angles $(\theta)$ between $60^{\circ}$ and $150^{\circ}$ pointing toward [-233] and [2-3-3]. The mesa depth $(d)$ is $30 \mathrm{~nm}$ for shallow- and $200 \mathrm{~nm}$ for deep-patterned substrates.

shallow-patterned (large-scale modifications due to steps) and deep-patterned (local modifications due to facets) substrates for formation of complex QD arrays.

\section{EXPERIMENTAL DETAILS}

The samples were grown by solid-source molecular beam epitaxy (MBE) on planar and artificially patterned GaAs (311)B substrates. To study the interaction of the natural directions of ordering and adatom surface migration on planar substrates with the anisotropic growth at patterned mesa sidewalls, ${ }^{11}$ stripe and zigzag patterns of various dimensions and orientations have been fabricated by optical lithography and wet chemical etching in the $\mathrm{H}_{2} \mathrm{SO}_{4}: \mathrm{H}_{2} \mathrm{O}_{2}: \mathrm{H}_{2} \mathrm{O}(1: 8: 1000)$ solution. The widths and separations of the periodic stripes, oriented along the [0-11] direction, were 2,4 , and $10 \mu \mathrm{m}$, as schematically depicted in Fig. 1(a), while that of the periodic zigzag patterns was $10 \mu \mathrm{m}$ with the mesa sidewalls alternately rotated plus and minus $15^{\circ}, 30^{\circ}$, and $60^{\circ}$ off $[0-11]$ [Fig. 1(b)]. The etched mesa depth was $30 \mathrm{~nm}$ for shallow-patterned substrates and $200 \mathrm{~nm}$ for deep-patterned substrates. The substrates were cleaned in concentrated $\mathrm{H}_{2} \mathrm{SO}_{4}$ and rinsed in ultrapure water before loading into the MBE growth chamber. The sample structure commenced with a $200 \mathrm{~nm}$ thick GaAs buffer layer grown at $580{ }^{\circ} \mathrm{C}$, followed by a ten period InGaAs/GaAs SL template.

Each of the ten SL periods comprised $3.3 \mathrm{~nm}$ InGaAs grown at $500{ }^{\circ} \mathrm{C}, 10 \mathrm{~s}$ growth interruption, thin capping by 0.5 (or 0.7 ) $\mathrm{nm} \mathrm{GaAs}$ at $500{ }^{\circ} \mathrm{C}$, annealing for $2 \mathrm{~min}$ at $600{ }^{\circ} \mathrm{C}$ under $\mathrm{As}_{4}$ flux, and growth of a 5.5(or 5.3) $\mathrm{nm} \mathrm{GaAs}$ separation layer at $600{ }^{\circ} \mathrm{C}$. The In composition was maintained between $40 \%$ and $45 \%$. On top of the SL template, the $3.3 \mathrm{~nm}$ InGaAs layer was repeated without annealing for formation of connected QD arrays, or $0.6 \mathrm{~nm}$ InAs was deposited at $480{ }^{\circ} \mathrm{C}$ (here, the thickness of the last GaAs spacer layer was increased to $15 \mathrm{~nm}$ ) for formation of isolated QD groups. Single InAs QDs were formed by increasing the growth temperature of the SL template and InAs QDs by about $30{ }^{\circ} \mathrm{C}$. The growth rates of $\mathrm{GaAs}$ and $\mathrm{InGaAs}$ were 0.073 and $0.132 \mathrm{~nm} / \mathrm{s}$, respectively, whereas that of InAs was $0.0013 \mathrm{~nm} / \mathrm{s}$. The $\mathrm{As}_{4}$ beam flux was maintained between $1.8 \times 10^{-6}$ and $2.4 \times 10^{-6}$ Torr. The structural properties of the samples were characterized by tapping-mode
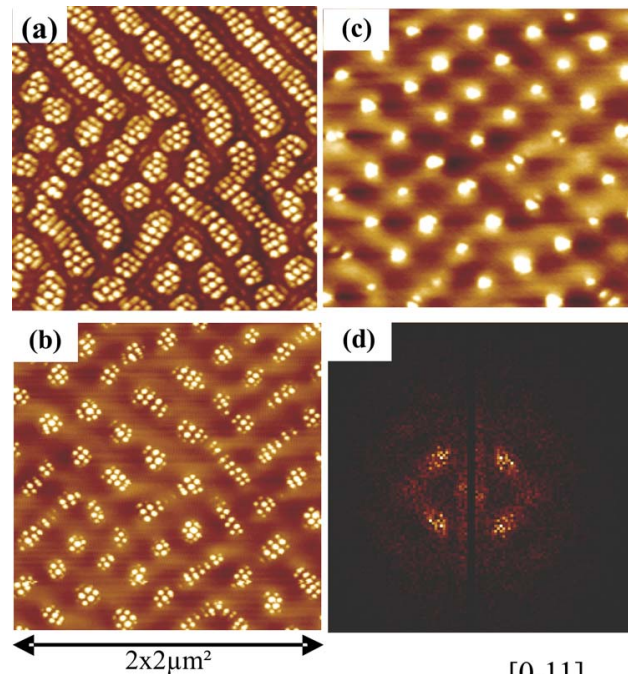

(d)

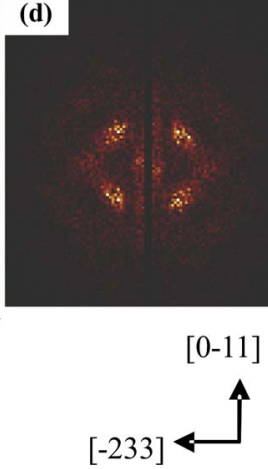

FIG. 2. (Color online) AFM height images of the (a) InGaAs QD arrays and (b) InAs QD groups on the InGaAs/GaAs SL template on planar substrates. (c) Single InAs QDs formed at increased growth temperature. (d) FFT of the AFM image of the single QDs in (c). The AFM height contrast is $20 \mathrm{~nm}$.

atomic force microscopy (AFM) in air. A series of InAs QD samples was capped by $100 \mathrm{~nm}$ GaAs for photoluminescence (PL) measurements. The PL was excited by the $512 \mathrm{~nm}$ line of a Nd:yttrium aluminum garnet laser with excitation power density of $256 \mathrm{~mW} / \mathrm{cm}^{2}$. A He-flow cryostat was used to control the temperature between $5 \mathrm{~K}$ and RT. The PL was dispersed by a single monochromator and recorded by a cooled InGaAs linear array detector.

\section{RESULTS AND DISCUSSION}

\section{A. InGaAs and InAs QD ordering on planar GaAs (311)B substrates}

For clarity, we briefly recall the SL template formation as well as InGaAs and InAs QD ordering on planar GaAs (311)B substrates, as described in Refs. 9 and 12. During SL template formation, the randomly distributed InGaAs QDs, after the first layer, develop into a distinct mesalike modulated InGaAs layer on a mesoscopic scale with increasing number of SL periods, generating the corresponding lateral strain field modulation on the SL template surface for QD ordering. Well-ordered periodic spotlike arrangements of connected InGaAs QD arrays and isolated InAs QD groups are formed on the SL template surface, which are aligned along the directions plus and minus $45^{\circ}$ off [0-11], as shown in Figs. 2(a) and 2(b). The average base diameter of the InAs QDs within the groups is $35 \mathrm{~nm}$ and their number varies between 5 and 7 . The number can be decreased to a single QD, shown in Fig. 2(c), by increasing the growth temperature. The lateral periodicity of the single QDs is $350 \mathrm{~nm}$, determined from the fast Fourier transform (FFT) analysis shown in Fig. 2(d), which is similar to that of the InAs QD groups. The areal density of the single QDs is $8.5 \mu \mathrm{m}^{-2}$. 

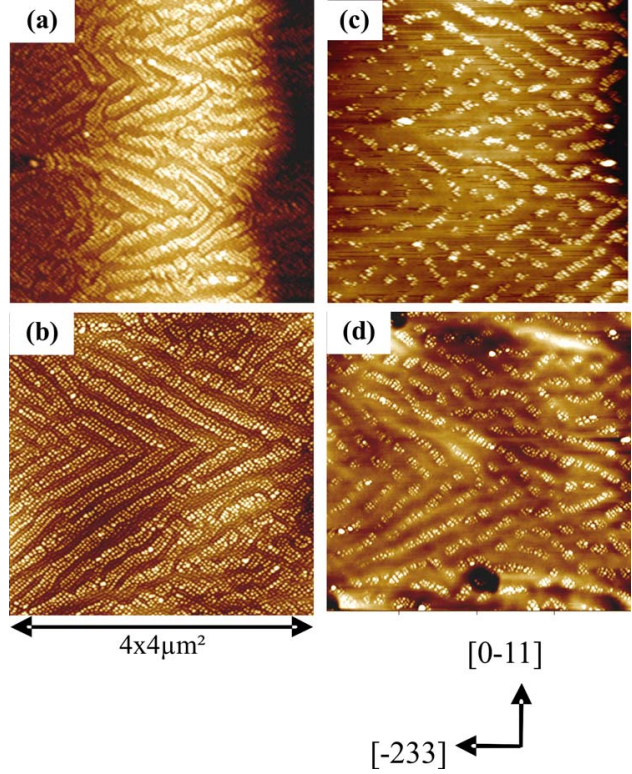

FIG. 3. (Color online) AFM height images of the [(a) and (b)] InGaAs QD arrays and [(c) and (d)] InAs QD groups on shallow-patterned substrates: [(a) and (c)] periodic stripes with $2 \mu \mathrm{m}$ stripe width and [(b) and (d)] zigzag with acute angle (mesa bottom) of $60^{\circ}$ pointing toward [2-3-3]. The height contrast is $30 \mathrm{~nm}$.

\section{B. InGaAs and InAs QD ordering on shallow- patterned GaAs (311)B substrates}

The lateral ordering of the InGaAs QD arrays and InAs QD groups distinctly changes when the SL template is grown on the shallow-patterned GaAs (311)B substrate. Figure 3 shows the InGaAs and InAs QD layers on the stripe- and zigzag-patterned substrates with stripe width of $2 \mu \mathrm{m}$ and acute zigzag angle of $60^{\circ}$. These patterns are chosen to show the most pronounced effects on the QD ordering, with the nonequivalent sidewalls of the [0-11] stripes most effectively breaking the symmetry of natural QD ordering and the $60^{\circ}$ zigzag sidewalls supporting the natural kink structure of the GaAs (311)B surface, discussed below. On the stripepatterned substrate the InGaAs QD arrays are arranged in periodic, well-ordered, and connected stripes assuming a zigzag pattern (on the inclined plane of the mesa stripes), shown in Fig. 3(a). The arrangement becomes uniform over macroscopic areas on the zigzag pattern (on the inclined plane with acute angle of the mesa bottom toward [2-3-3]), shown in Fig. 3(b). The InAs QD groups, depicted in Figs. 3(c) and 3 (d), follow the same arrangement of zigzags of linear stripes while remaining well isolated.

The stripes of InGaAs QD arrays and InAs QD groups follow the direction of typical triangular shaped defect structure for the (311)B surface orientation with acute angle pointing toward [2-3-3], which is toward the next [111] plane. ${ }^{11}$ Hence, the underlying kink structure of the steps induced on the inclined surface of the shallow mesa sidewalls (the inclination is less than $1^{\circ}$ ) is assigned to govern the direction of In and $\mathrm{Ga}$ adatom surface migration in SL template formation during annealing, and thus, the direction of the lateral strain field modulation leading to the zigzag stripelike arrangement of InGaAs QD arrays and InAs QD groups on the shallow stripe- and zigzag-patterned substrates.
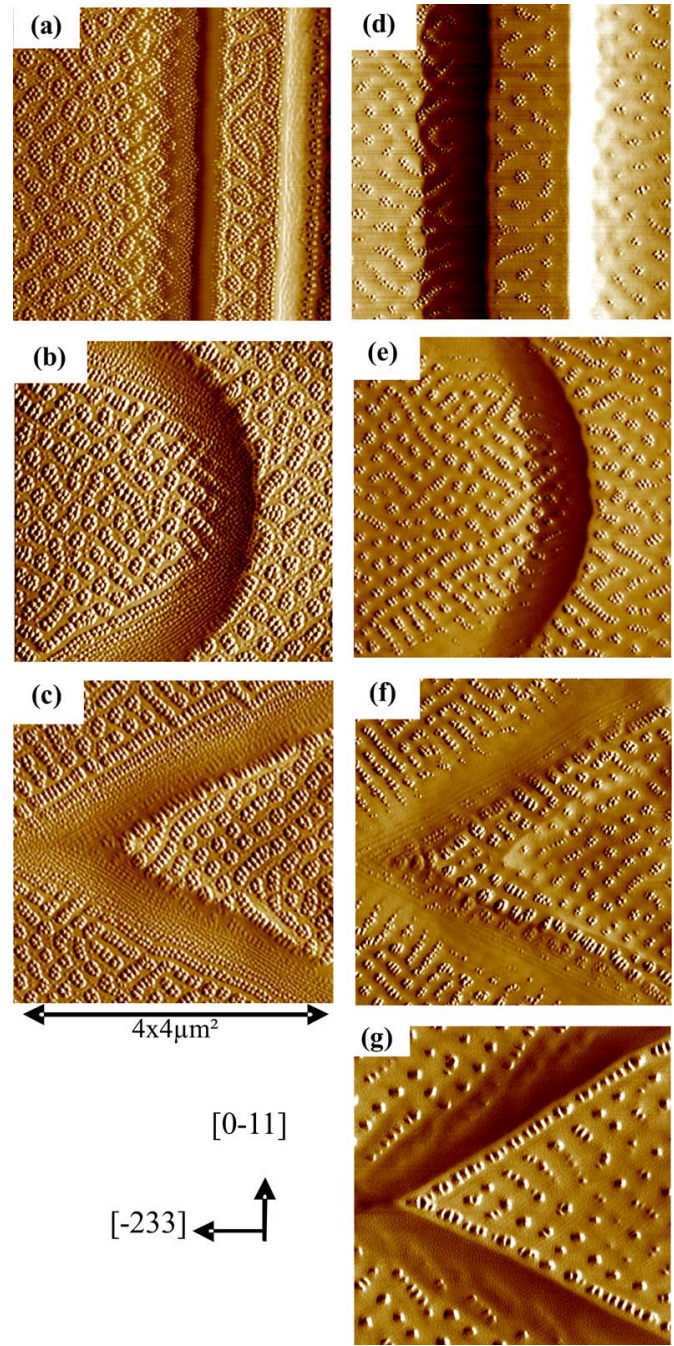

FIG. 4. (Color online) AFM slope images of the [(a)-(c)] InGaAs QD arrays and [(d)-(f)] InAs QD groups on deep-patterned substrates: [(a) and (d)] periodic stripes with $2 \mu \mathrm{m}$ stripe width, [(b) and (e)] zigzag with acute angle (mesa bottom) of $60^{\circ}$ pointing toward [2-3-3], and [(c) and (f)] zigzag with acute angle (mesa top) of $60^{\circ}$ pointing toward [-233]. (g) Single InAs QDs on deep-zigzag-patterned substrate with acute angle (mesa top) of $60^{\circ}$ pointing toward [-233]. AFM slope images are shown to reveal the QDs.

\section{InGaAs and InAs QD ordering on deep-patterned GaAs (311)B substrates}

In contrast to the lateral QD ordering on the inclined stepped surfaces on the shallow-patterned substrates, the large-scale ordering on the GaAs (311)B top and bottom surfaces on the deep-patterned substrates remains unchanged, as illustrated in Fig. 4. The formation of slow-growing side facets ${ }^{11}$ produces areas which are free of QDs, and the ordering of the InGaAs QD arrays and InAs QD groups on the GaAs (311)B top and bottom surfaces is modified only close to the side facets [Figs. 4(a) and 4(d)]. This is attributed to the selectivity of growth on faceted surfaces leading to preferential adatom surface migration from the slow-growing side facets to the mesa top and bottom areas. The top and bottom areas remain planar at distances longer than the adatom surface diffusion length (of the order of $1 \mu \mathrm{m}$ ) away from the side facets, while within this distance, the growth rate enhancement produces inclined surfaces with steps to modify the QD ordering similar to the steps generated on 

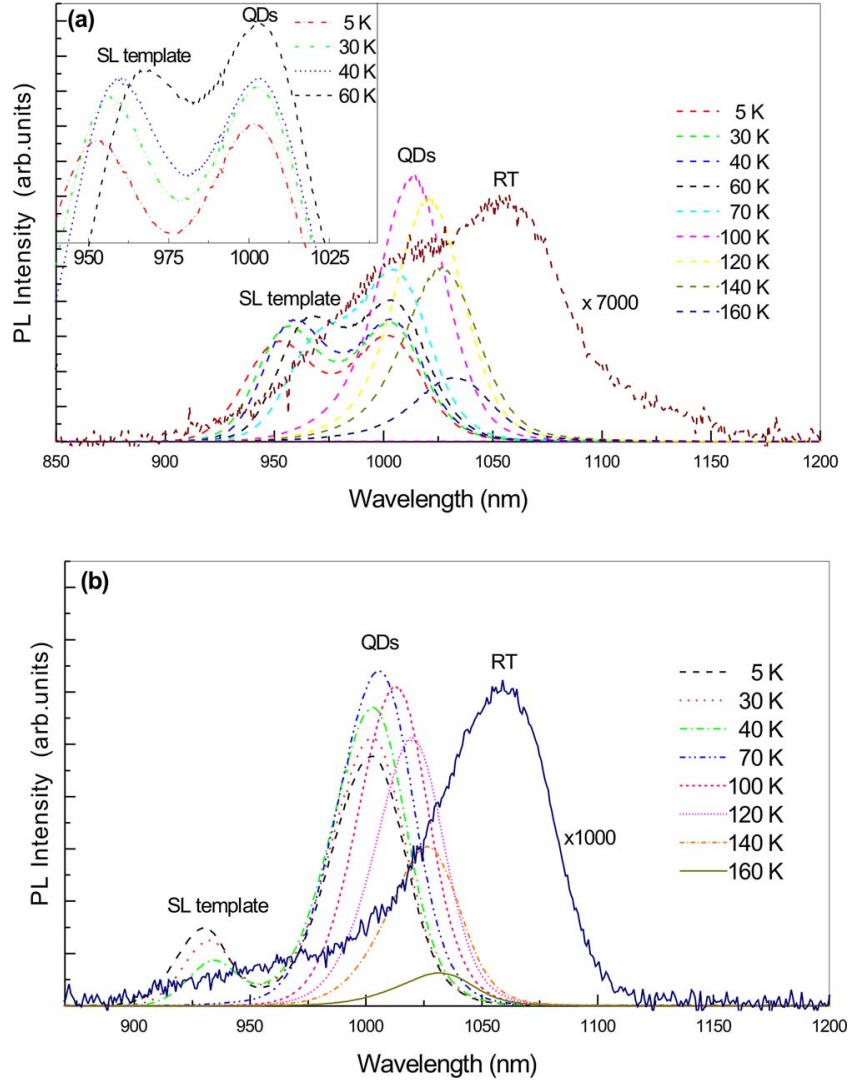

FIG. 5. (Color online) Temperature dependent PL spectra of the InAs QD groups on (a) shallow- and (b) deep-patterned substrates.

shallow-patterned substrates. Depending on the orientation of the side facets, the InGaAs and InAs QDs arrange in stripes of connected InGaAs QD arrays and isolated InAs QD groups close to the side facets, which are most pronounced on zigzag patterns with acute angle toward [2-3-3], shown in Figs. 4(b) and 4(e) or [-233], shown in Figs. 4(c) and $4(\mathrm{f})$.

The combination of self-organized anisotropic strain engineering with growth on patterned substrates is directly applied to produce complex arrangements of single InAs QDs. On the deep-patterned substrate the QDs order into single-QD stripes along the zigzag edges on the mesa top, shown in Fig. 4(g). Hence, while shallow patterns allow modifications of the QD ordering within large areas, the deep patterns allow local modifications, revealing the complementary nature of both approaches for formation of complex QD arrays.

\section{OPTICAL PROPERTIES OF INAS QD GROUPS ON THE PATTERNED SUBSTRATES}

Figure 5 shows the temperature dependent PL spectra of the InAs QD groups on the (a) shallow- and the (b) deeppatterned substrates. At $5 \mathrm{~K}$ the PL line centered at $1000 \mathrm{~nm}$ stems from the InAs QD groups and that at shorter wavelength $(950 \mathrm{~nm}$ on shallow- and $925 \mathrm{~nm}$ on deep-patterned substrate) from the SL template. With increasing temperature, the PL intensity from the QDs increases between 5 and $60-70 \mathrm{~K}$ due to thermally activated carrier transfer from the SL template to the QDs on both substrates. On the shallow- patterned substrate the PL intensity of the SL template first increases between 5 and $60 \mathrm{~K}$ before it drops, as depicted in the inset of Fig. 5(a). In contrast, on the deep-patterned substrate the PL intensity of the SL template decreases from the lowest temperature on, similar to the behavior on unpatterned substrates. ${ }^{12}$ The energy separation between QDs and SL template PL is smaller on the shallow-patterned substrate, leading to thermal repopulation of the SL template at RT. These differences are attributed to the presence of steps and the resulting modification of the SL template on the shallowpatterned substrate. The steps of varying direction and density modify the QD ordering due to the local modification of the In and $\mathrm{Ga}$ adatom surface migration during annealing, which likely produces lateral thickness and composition fluctuations in the SL template. This leads to stronger carrier localization-delocalization effects within the SL template itself, initially increasing the template PL intensity with temperature, and to a redshift of the PL originating from regions of largest thickness and In composition. Between $70 \mathrm{~K}$ and RT the PL efficiency of the QDs drops about three to four orders of magnitude due to thermal escape of carriers to the GaAs barriers. This is very similar to the behavior of the InAs QD groups on planar substrates evidencing no degradation of the optical quality of the QD groups on the patterned substrates.

\section{CONCLUSION}

In conclusion, we have studied guided self-organized anisotropic strain engineering for formation of complex laterally ordered InGaAs QD arrays and InAs QD groups grown on shallow- and deep-patterned GaAs (311)B substrates by MBE. The combination of strain and step engineerings on shallow stripe-patterned substrates transforms the periodic spotlike arrangement of the InGaAs QD arrays and InAs QD groups (on planar substrates) into a zigzag arrangement of periodic stripes which are well ordered over macroscopic areas on zigzag mesa-patterned substrates. In contrast, on deep-patterned substrates, the formation of slow-growing facets produces mesa sidewalls which are free of QDs. The arrangements of the InGaAs QD arrays and InAs QD groups on the GaAs (311)B top and bottom planes are modified only close to the sidewalls depending on the sidewall orientation. The QDs on the shallow- and deep-patterned substrates exhibit excellent optical properties up to room temperature. Therefore, the concept of guided self-organization demonstrated on shallow-patterned (large scale modification due to steps) and deep-patterned (local modification due to facets) substrates is established for creation of complex architectures of laterally ordered QDs for future quantum functional devices.

${ }^{1}$ R. Nötzel, T. Mano, Q. Gong, and J. H. Wolter, in Nanoelectronics and Nanoscale Processing, special issue of Proc. IEEE 91, 1898 (2003), and references therein.

${ }^{2}$ W. Seifert, N. Carlsson, A. Petersson, L.-E. Wernersson, and L. Samuelson, Appl. Phys. Lett. 68, 1684 (1996).

${ }^{3}$ H. Lee, J. A. Johnson, J. S. Speck, and P. M. Petroff, J. Vac. Sci. Technol. B 18, 2193 (2000)

${ }^{4}$ Y. Nakamura, O. G. Schmidt, N. Y. Jin-Phillipp, S. Kiravittaya, C. Müller, K. Eberl, H. Gräbeldinger, and H. Schweizer, J. Cryst. Growth 242, 339 
(2002).

${ }^{5}$ T. Mano, R. Nötzel, G. J. Hamhuis, T. J. Eijkemans, and J. H. Wolter, Appl. Phys. Lett. 81, 1705 (2002).

${ }^{6}$ T. v. Lippen, R. Nötzel, G. J. Hamhuis, and J. H. Wolter, Appl. Phys. Lett. 85, 118 (2004).

${ }^{7}$ Q. Xie, A. Madhukar, P. Chen, and N. P. Kobayashi, Phys. Rev. Lett. 75, 2542 (1995).

${ }^{8}$ G. S. Solomon, J. A. Trezza, A. F. Marshall, and J. S. Harris, Jr., Phys. Rev. Lett. 76, 952 (1996).
${ }^{9}$ T. Mano, R. Nötzel, D. Zhou, G. J. Hamhuis, T. J. Eijkemans, and J. H. Wolter, J. Appl. Phys. 97, 014304 (2005).

${ }^{10}$ E. Selcuk, T. v. Lippen, G. J. Hamhuis, and R. Nötzel, J. Cryst. Growth 301-302, 701 (2007).

${ }^{11}$ R. Nötzel, M. Ramsteiner, J. Menniger, A. Trampert, H.-P. Schönherr, L. Däweritz, and K. H. Ploog, J. Appl. Phys. 80, 4108 (1996).

${ }^{12}$ T. v. Lippen, R. Nötzel, G. J. Hamhuis, and J. H. Wolter, J. Appl. Phys. 97, 014304 (2005). 